\title{
CTX-M-14 $\beta$-lactamase-producing Citrobacter freundii isolated in Venezuela
}

Beatriz Millán, Bárbara Ghiglione², Tulia Díaz ${ }^{1,3}$, Gabriel Gutkind ${ }^{2}$ and María Araque 1* $^{*}$

\begin{abstract}
A clinical isolate of $C$. freundii with reduced susceptibility to extended-spectrum $\beta$-lactams from a woman with cystocele associated with recurrent urinary tract infection was analyzed. Susceptibility tests, double disk synergy tests (DDST) and enzymatic activity by the agar iodometric method suggested the presence of ESBLs. Conjugation experiments revealed the presence of a large conjugative plasmid (pLM07/20) with an exclusive FrepB replicon type (IncF/FIB). PCR analysis and sequencing confirmed the presence of the bla $a_{\mathrm{CTX}-\mathrm{M}-14}$ gene in the pLM07/20 from C. freundii.LM07/10. Although this is the first report of CTX-M-14 in Venezuela, we alert the medical community that future increase of these $\beta$-lactamases in our city could be due to dissemination of plasmids into bacterial populations.
\end{abstract}

Keywords: Citrobacter freundii, Extended-spectrum $\beta$-lactamases, CTX-M-14, plasmid, FrepB replicon

\section{Background}

Extended-spectrum $\beta$-lactamases (ESBLs) create significant therapeutic problems by inactivating almost all $\beta$ lactams except cephamycins and carbapenems. Following the detection of the first ESBL, TEM and SHVderived ESBLs evolved and disseminated globally up to the late 1990s. Since then, a new epidemiological situation lead to a predominant increase of CTX-M derived enzymes [1]. Infections caused by ESBL-producing Enterobacteriaceae have mostly been described as hospital-acquired, associated with health care facilities [2], and, with increasing frequency, isolated from patients from both extended-care facilities and community-onset diseases [3,4]. Citrobacter freundii is an opportunistic pathogen that can cause diarrhea, septicemia, meningitis, and respiratory and urinary tract infection, especially in high-risk groups [5]. Multidrug resistance in Citrobacter spp. is a growing concern all over the world, and extended-spectrum cephalosporins are currently used to treat infections caused by these microorganisms. Numerous international molecular studies have also described the occurrence of various CTX-M types in species of Citrobacter, CTX-M-9 in the United Kingdom

\footnotetext{
* Correspondence: araquemc@ula.ve

'Laboratorio de Microbiología Molecular, Facultad de Farmacia y Bioanálisis, Universidad de Los Andes, Mérida, Venezuela

Full list of author information is available at the end of the article
}

[6], CTX-M-30 in Canada [7], CTX-M-3 in Korea [8], CTX-M-2 in Japan [9], CTX-M-14 in China [10], and CTX-M-15 in India [11]. However, the distribution of CTX-M producers among community-onset pathogens from South America, especially in Venezuela, remains scarcely known. In this report, we describe a clinical isolate of $C$. freundii with reduced susceptibility to extended-spectrum cephalosporins that produces a CTX-M-14 type $\beta$-lactamase, from a woman with cystocele and urinary infection.

\section{Case presentation}

In June 2010, a 47-year-old woman was assisted in private consulting with a history of grade II cystocele and recurrent urinary tract infection since December 2009. One cephalosporin-resistant strain of Citrobacter freundii LM07/10 was isolated from an urine sample. The strain was identified using conventional biochemical tests and confirmation was realized by API 20E system (bioMérieux, Marcy l'Etoile, France). The patient was treated according to the susceptibility test with i.v. meropenem. Also, a surgical treatment to repair the anterior vaginal wall prolapse was suggested.

Antimicrobial susceptibility testing was determined using the agar dilution method according to the recommendations of the Clinical and Laboratory Standards Institute (CLSI) [12]. The following antimicrobials 
(Valmorca, Mérida, Venezuela) were tested: cefoxitin, cefotaxime, ceftazidime, ceftazidime plus clavulanic acid, aztreonam, imipenem, meropenem, ciprofloxacin, gentamicin, amikacin and tobramycin. The ESBL phenotype was detected by the double disk (Oxoid, Basingstoke, Hampshire, England) synergy test (DDST) according to CLSI [12] guidelines. The quality control strains used were Escherichia coli ATCC 25922 (negative control for ESBL) and Enterobacter cloacae UBA-G CTX-M-9 (positive control for ESBL). $\beta$-lactamase presence in crude extracts obtained by sonication was confirmed by an agar iodometric method [13] with minor modifications [14] using cefotaxime as substrate.

To determine whether the resistance was transferable, conjugation experiments using mixed broth cultures were performed with $E$. coli $\mathrm{J} 53$ (azide ${ }^{\mathrm{R}}$ ) as recipient. Transconjugants were selected on Levine agar (Britania, Buenos Aires, Argentina) plates containing $75 \mu \mathrm{g} / \mathrm{ml}$ of azide and $2 \mu \mathrm{g} / \mathrm{ml}$ of cefotaxime. The presence of $b l a_{\mathrm{CTX}-\mathrm{M}}$ genes in the transconjugants was confirmed by DDST and PCR. Plasmid DNA from transconjugants was extracted by the rapid alkaline lyses method [15] and then analyzed by electrophoresis on a $0.8 \%$ agarose gel and visualized by staining with ethidium bromide under UV light. Identification of plasmids by PCR-based replicon typing was carried out as described by Carattoli et al. [16].

Detection of antimicrobial resistance $b l a_{\mathrm{CTX}-\mathrm{M}}$ and $b l a_{\text {CTX-M-9 }}$ genes were performed by PCR amplification using the following primers sets [17]: CTX-M-GF-5'ATG TGC AGY ACC AGTA ARG TKA TGG C ' 3 and CTXM-GR- 5’ CCG CTG CCG GTY TTA TCV CCB AC ‘3 for bla $a_{\text {CTX-M }}$; CTX-M-9F-5'AAC ACG GAT TGA CCG TCT TG '3 and CTX-M-9R-5' TTA CAG CCC TTC

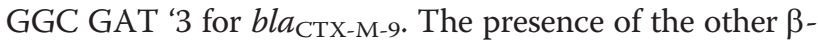
lactamase genes was determined by previously described primers [11]. DNA templates were prepared by suspending one or two fresh colonies in $200 \mu \mathrm{l}$ of sterile distilled water and heating at $95^{\circ} \mathrm{C}$ for $10 \mathrm{~min}$. Amplification was performed in a final volume of $25 \mu \mathrm{l}$ containing $1 \mu \mathrm{M}$ of each primer, $0.2 \mathrm{mM}$ of dNTPs, $1.5 \mathrm{mM} \mathrm{MgCl}_{2}$ and 1 unit of Taq polymerase. PCR products were visualized by electrophoresis on $1 \%$ agarose gels, stained with ethidium bromide $(50 \mu \mathrm{g} / \mathrm{ml})$ and photographed with UVP Biodoc-It System. Amplification products were purified (Sigma PCR Cleanup kit) and their nucleotide sequencing was performed with the ABI Prism 377 genetic analyzer (Applied Biosystems, CA, USA). Nucleotide and amino acid sequence alignments were analyzed using the Basic Local Alignment Search Tool (BLAST) suite of programs (http://www.ncbi.nlm.nih.gov/BLAST.cgi).

\section{Discussion}

Recurrent urinary tract infection (UTI) remains an important public health problem in women of all ages
[18]. We reported a case of a woman with grade II cystocele associated with recurrent UTI. This patient had more than three microbiologically documented episodes of symptomatic UTI during the last 6 months. Initially the patient was managed with empirical first line antibiotic therapy (amoxicillin or cephalexin) and later with extended-spectrum cephalosporins (ceftriaxone or cefotaxime). Recurrent infections are of particular concern because of the repeated morbidity and necessity for frequent administration of antibiotics with the possible adverse consequences of selection of antimicrobial-resistant strains.

A clinical isolate of $C$. freundii with reduced susceptibility to extended-spectrum $\beta$-lactam was collected from the patient urine sample. This isolate showed a multidrug resistance phenotype including ceftriaxone, cefotaxime, gentamicin, tobramycin and ciprofloxacin, but was completely susceptible to carbapenems. The DDST and enzymatic activity by the agar iodometric method suggested the presence of ESBL, which was confirmed by restored susceptibility to cefotaxime in the presence of clavulanic acid (Table 1). All resistance (or reduced susceptibility) markers were transferable by conjugation to recipient E. coli (J53 azide ${ }^{\mathrm{R}}$ ), except ciprofloxacin. In this study, C. freundii harbored a plasmid of $>150 \mathrm{~kb}$ with a FrepB replicon belonging to the IncF/FIB group. The identification of a family of related plasmids has important public health implications since it demonstrates that broad-host range plasmids carrying resistance to clinically relevant antibiotics can spread worldwide among bacteria responsible of both nosocomial and community-acquired infections [19].

Further DNA templates of C. freundii LM07/10, E. coli J53-07/20 transconjugants and plasmid (pLM07/20) were screened by PCR assays for bla $a_{\mathrm{TEM}}, b l a_{\mathrm{SHV}}$ and bla $a_{\mathrm{CTX}-\mathrm{M}}$ genes. Primers specific to the $b l a_{\mathrm{CTX}-\mathrm{M}-9}$ group gave positive gene amplification (850 bp fragment). Sequence analysis of the amplification product revealed the presence of $b l a_{\mathrm{CTX}-\mathrm{M}-14}$.

ESBLs-producing Enterobacteriaceae were previously identified in the small number of studies of venezuelan hospital-derivated isolates [20-23]. Previous reports of genotypes of ESBL genes from Venezuela were sporadic and involved SHV-5 and CTX-M-2, being particularly common in Klebsiella pneumoniae of nosocomial origin [20-22]. Also, the distribution of different genotypes of ESBLs in hospital or community in Venezuela is poorly understood. This is the first report of a CTX-M-14 $\beta$-lactamase producing $C$. freundii in Venezuela associated with a large conjugative plasmid with an exclusive FrepB replicon type (IncF/FIB) isolated from a community patient. But previous studies indicated that others replicons of different incompatibility groups (IncI or IncK) can also be involved in the dissemination of CTX-M-14 [24,25]. 
Table 1 Antibiotic susceptibility (MIC) of ESBL-producing Citrobacter freundii LM07/10 and Escherichia coli J53-07/20 transconjugants

\begin{tabular}{|c|c|c|c|c|}
\hline $\begin{array}{l}\text { Antibiotics } \\
\text { tested }\end{array}$ & $\begin{array}{l}\text { C. freundii } \\
\text { LM07/10 } \\
\text { MIC }(\mu \mathrm{g} / \mathrm{ml})\end{array}$ & $\begin{array}{c}\text { E. coli J53-07/20 } \\
\text { transconjugants } \\
\text { MIC }(\mu \mathrm{g} / \mathrm{ml})\end{array}$ & $\begin{array}{l}\text { E. coli J53 } \\
\text { MIC }(\mu \mathrm{g} / \mathrm{ml})\end{array}$ & $\begin{array}{c}\text { E. coli } \\
\text { ATCC } 25922 \\
\text { MIC }(\mu \mathrm{g} / \mathrm{ml}) \\
\end{array}$ \\
\hline Cefoxitin & 8 & 8 & 4 & 4 \\
\hline Cefotaxime & $>16$ & 8 & 0.064 & 0.125 \\
\hline Cefotaxime/clavulanic acid* & 0.25 & 0.25 & 0.125 & 0.125 \\
\hline Ceftazidime & 2 & 1 & 0.025 & 0.5 \\
\hline Ceftazidime/clavulanic acid* & 0.25 & 0.25 & 0.25 & 0.125 \\
\hline Aztreonam & 4 & 4 & 0.25 & 0.25 \\
\hline Imipenem & 0.064 & 0.064 & 0.064 & 0.032 \\
\hline Meropenem & 0.064 & 0.064 & 0.064 & 0.064 \\
\hline Gentamicin & $>64$ & 32 & 0.5 & 0.5 \\
\hline Amikacin & 8 & 4 & 0.5 & 1 \\
\hline Tobramycin & 16 & 4 & 0.25 & 1 \\
\hline Ciprofloxacin & $>16$ & 0.025 & 0.25 & 0.064 \\
\hline \multicolumn{5}{|l|}{ Other test } \\
\hline $\mathrm{DDST}^{* *}$ & + & + & - & - \\
\hline
\end{tabular}

* Clavulanate was used at fixed concentration of $4 \mu \mathrm{g} / \mathrm{ml}$.

** DDST: double disk synergy test.

Recent studies suggest that infections due to ESBLsproducing organisms might be an emerging problem in outpatient settings in different countries $[3,26]$. Few data regarding the molecular epidemiology of CTX-M type ESBLs-producing C. freundii isolated from patient with community-onset infections are available $[17,26]$. According to the findings from this study, we may assume the hypothesis that microorganisms with antibiotic resistance mechanisms can be present in patients in the community and it is possible that healthy people could act as a reservoir of these ESBLs as a consequence of antibiotic use and abuse. Only through the recognition of factors associated with increasing resistance and the study of the molecular mechanisms involved, strategies can be traced and $\beta$-lactam resistance minimized.

In conclusion, this study supports the view that CTXM-14 producing $C$. freundii is an emerging pathogen in community settings in Mérida, Venezuela, and that increased efforts in surveillance and study of risk factors associated with these bacteria are needed.

\section{Consent}

Patient's written informed consent was obtained for publication of this case report. A copy of the written consent is available for review by the Editor-in-Chief of this journal.

\section{Acknowledgements}

This study was carried out within the research activities of the Bacterialnet project, ALFA II Contract No II-531-FC-FA-FCD-FI and partially supported by Consejo de Desarrollo Científico, Humanístico y Tecnológico (CDCHT-ULA) of University of The Andes, Mérida-Venezuela (grant CVI-ADG-FA-02-97).

\section{Author details}

${ }^{1}$ Laboratorio de Microbiología Molecular, Facultad de Farmacia y Bioanálisis, Universidad de Los Andes, Mérida, Venezuela. ${ }^{2}$ Cátedra de Microbiología, Facultad de Farmacia y Bioquímica, Universidad de Buenos Aires, Buenos Aires, Argentina. ${ }^{3}$ Laboratorio de Síndromes Gastrointestinales y Urinarios, Facultad de Farmacia y Bioanálisis, Universidad de Los Andes, Mérida, Venezuela.

\section{Authors' contributions}

BM and BG carried out susceptibility test and molecular studies. TD performed isolation and microbiological identification of bacteria. GG and MA were involved in study conception and design, critical discussion, writing and review of the manuscript. All authors have read and approved the final manuscript.

\section{Competing interests}

The authors declare that they have no competing interests.

Received: 27 April 2011 Accepted: 31 May 2011 Published: 31 May 2011

References

1. Pitout JDD: Infections with extended-spectrum $\beta$-lactamase-producing Enterobacteriaceae. Changing epidemiology and drug treatment choices. Drugs 2010, 70(3):313-333.

2. Falagas ME, Karageorgopoulos DE: Extended-spectrum $\beta$-lactamaseproducing organisms. J Hosp Infect 2009, 73:345-354.

3. Rodríguez-Baño J, Pascual A: Clinical significance of extended-spectrum $\beta$ lactamases. Expert Rev Anti Infect Ther 2008, 6(5):671-683.

4. Rossi A. Galas M, Corso A, Radice M, Rivas M, Caffer M, Binztein N, Gutkind G: Unussual multiresistant Vibrio cholerae $\mathrm{O} 1$ var. El Tor in Argentina. Lancet 1993, 342:1172-1173.

5. Lavigne JP, Defez C, Bouziges N, Mahamat A, Sotto A: Clinical and molecular epidemiology of multidrug-resistant Citrobacter spp. infections in a French university hospital. Eur J Clin Microbiol Infect Dis 2007, 26:439-441.

6. Munday CJ, Whitehead GM, Todd NJ, Campbell M, Hawkey PM: Predominance and genetic diversity of community- and hospital acquired CTX-M extended-spectrum $\beta$-lactamases in York, UK. J Antimicrobial Chemother 2004, 54:628-633.

7. Abdalhamid B, Pitout JDD, Moland ES, Hanson ND: Community-onset disease caused by Citrobacter freundii producing a novel CTX-M $\beta$ - 
lactamase, CTX-M-30, in Canada. Antimicrob Agents Chemother 2004, 48:4435-4437.

8. Kim J, Lim YM: Prevalence of derepressed AmpC mutants and extendedspectrum $\beta$-lactamase producers among clinical isolates of Citrobacter freundii, Enterobacter spp., and Serratia marcescens in Korea: dissemination of CTX-M-3, TEM-52, and SHV-12. J Clin Microbiol 2005, 43:2452-2455.

9. Muta T, Tsuruta N, Seki Y, Ota R, Suzuki S, Shibata N, Kato K, Eto T, Gondo H, Arakawa Y: A nosocomial outbreak due to novel CTX-M-2producing strains of Citrobacter koseri in a hematological ward. Jpn J Infect Dis 2006, 59:69-71.

10. Zhang R, Yang L, Cai JC, Zhou HW, Chen GX: High level carbapenem resistance in a Citrobacter freundii clinical isolate is due to a combination of KPC-2 production and porin expression. J Med Microbiol 2008, 57:332-337.

11. Shahid M: Citrobacter spp. simultaneously harboring $b l a_{\mathrm{CTX}-\mathrm{M}}, b l a_{\mathrm{TEM}}$, $b l a_{\mathrm{SHV}}, b / a_{\mathrm{ampC}}$ and insertion sequences IS26 and orf513: an evolutionary phenomenon of recent concern for antibiotic resistance. $J$ Clin Microbiol 2010, 48:1833-1838.

12. Clinical and Laboratory Standards Institute (CLSI): Performance standards for antimicrobial susceptibility testing, 21th informational supplement. CLSI Document M100-S20. Wayne, PA. 2011.

13. Labia R, Barthélémy M: Beta-lactamase enzymogram": an agar adaptation of the iodometric method. Ann Microbiol 1979, 30B(3):295-304.

14. Rossi A, Lopardo H, Picandet AM, Mariño M, Galds M, Radice M, Gutkind G: Non-Typhoid Salmonella spp. resistant to cefotaxime. J Antimicrobial Chemother 1995, 36(4):697-702.

15. Birnboim HC, Doly J: A rapid alkaline extraction procedure for screening recombinant plasmid DNA. Nucleic Acid Res 1979, 7:1513-1523.

16. Carattoli A, Bertini A, Villa L, Falbo V, Hopkins KL, Threlfall EJ: Identification of plasmids by PCR-based replicon typing. J Microbiol Methods 2005, 63:219-228.

17. Minarini $L A R$, Poirel L, Trevisani NAC, Darini ALC, Nordmann P: Predominance of CTX-M-type extended-spectrum $\beta$-lactamase genes among enterobacterial isolates from outpatients in Brazil. Diagn Microbiol Infect Dis 2009, 65:202-206.

18. Raz R, Gennesin Y, Wasser J, Stoler Z, Rosenfeld S, Rottensterich E, Stamm WE: Recurrent urinary tract infections in postmenopausal women. Clin Infect Dis 2000, 30:152-156.

19. Carattoli A: Resistance plasmid families in Enterobacteriaceae. Antimicrob Agents Chemother 2009, 53:2227-2238

20. Araque M, Nieves B, Lauretti L, Rossolini GM: Molecular basis of extendedspectrum $\beta$-lactamase production in nosocomial isolates of Klebsiella pneumoniae from Mérida, Venezuela. Int J Antimicrob Agents 2000, 15:37-42.

21. Araque M, Rivera I: Simultaneous presence of $b l a_{\mathrm{TEM}}$ and $b l a_{\mathrm{SHV}}$ genes on a large conjugative plasmid carried by extended-spectrum $\beta$-lactamaseproducing Klebsiella pneumoniae. Am J Med Sci 2004, 327:118-122.

22. Guzmán M, Alonso G: Caracterización de $\beta$-lactamasas de espectro extendido (BLEE) en cepas nosocomiales de K. pneumoniae. SucreVenezuela. Inves Clin 2009, 50:419-431.

23. Torres L, Gagliotta V, Torres O, Benitez M, Dominguez M, Pedroza R: $\beta$ lactamasa de espectro expandido en enterobacterias aisladas en centros de salud de Caracas. Rev Soc Venez Microbiol 2006, 26:80-88.

24. Marcadé G, Deschamps C, Boyd A, Gautier V, Picard B, Branger C, Denamur E, Arlet G: Replicon typing of plasmids in Escherichia coli producing extended-spectrum $\beta$-lactamases. J Antimicrob Chemother 2009, 63:67-71.

25. Valverde A, Cantón R, Garcillán-Barcia MP, Novais A, Galán JC, Alvarado A, de la Cruz F, Baquero F, Coque TM: Spread of bla $a_{\mathrm{CTX}-\mathrm{M}-14}$ is driven mainly by IncK plasmids disseminated among Escherichia coli phylogroups A, B1, and D in Spain. Antimicrob Agents Chemother 2009, 53:5204-5212.

26. Pitout JDD, Gregson DB, Church DL, Elsayed S, Laupland KV: Communitywide outbreaks of clonally related CTX-M-14 $\beta$-lacatmase-producing Escherichia coli strains in the Calgary health region. J Clin Microb 2005, 43:2844-2849.

doi:10.1186/1476-0711-10-22

Cite this article as: Millán et al:: CTX-M-14 $\beta$-lactamase-producing Citrobacter freundii isolated in Venezuela. Annals of Clinical Microbiology and Antimicrobials 2011 10:22.

\section{Submit your next manuscript to BioMed Central and take full advantage of:}

- Convenient online submission

- Thorough peer review

- No space constraints or color figure charges

- Immediate publication on acceptance

- Inclusion in PubMed, CAS, Scopus and Google Scholar

- Research which is freely available for redistribution 